\title{
Numerical Study of the Mechanical Behavior of Polyamide 66 Reinforced by Argan Nut Shell Particles with the Finite Element Method and the Mori-Tanaka Model
}

\author{
Aziz Moumen ${ }^{1}$, Abdelghani Lakhdar ${ }^{2}$, Khalifa Mansouri $^{3}$ \\ ${ }^{1}$ Laboratory of SSDIA, Hassan II University of Casablanca, Higher Normal School of Technical Education, \\ Mohammedia, Morocco.Moumenaziz1@ gmail.com \\ ${ }^{2}$ Laboratory of SSDIA, Hassan II University of Casablanca, Higher Normal School of Technical Education, \\ Mohammedia, Morocco.Lakhdarabdelghani11@gmail.com \\ ${ }^{3}$ Laboratory of SSDIA, Hassan II University of Casablanca, Higher Normal School of Technical Education, \\ Mohammedia, Morocco.Khmansouri@hotmail.com
}

\begin{abstract}
The bio-loading of materials is a research axis that has been very well studied in recent years in order to meet the needs of industrialists, the requirements of regulations, environmental constraints and sustainable development, unlike classical loads having a harmful effect on the environment in addition to their high density and high cost.

In this numerical modeling, we studied the mechanical behavior of Nylon PA66 reinforced by Argan Nut Shell particles (ANS) using the Finite Element method in comparison with the Mori-Tanaka model. The numerical modeling results show that these particles are rigid elastic having a Young's modulus of $8150 \mathrm{MPa}$ and a stress at break of 244.5 MPa. The reinforcement of Nylon PA66 by ANS particles has better elastic properties compared to the pure state. Young's modulus improves from $3282 \mathrm{MPa}$ to 3950 $\mathrm{MPa}$ by the finite element method and $3853.6 \mathrm{MPa}$ by the Mori-Tanaka model. The stress at break also improves from 98.46 MPa to $118.5 \mathrm{MPa}$ by the first method and $115.6 \mathrm{MPa}$ by the second model.

The study of the different parameters on the final behavior of the bio composite shows that the mechanical characteristics of the bio composite become more optimal by adding more particle content $(\mathrm{Wt} \%)$ at an optimal value of $20 \mathrm{Wt} \%$ and by decreasing the Argan Nut Shell particles size. This bio load of natural origin will therefore be considered as an alternative for classical loads in order to obtain an environment friendly eco composite with much better mechanical properties.
\end{abstract}

Key words: Bio composite, Argan Nut Shell particles, Polyamide 66, Environment, Sustainable development, Finite Element method, Mori Tanaka model.

\section{INTRODUCTION}

The reinforcement of polymers by classical loads presents several drawbacks like having minor properties than natural loads, such as high weight and cost, low biodegradability and a harmful effect to the environment [1].

In order to meet the requirements of manufacturers, regulations, environmental constraints and sustainable development, researchers in the field of materials have recently been working on bio-loading using natural fillers which are friendly to the environment and offer more rigidity, lower cost, simple extraction process and no health issues to workers unlike the classical loads requiring a lot of safety precaution [1].

We are going to study polyamide PA66 offering a light weight and a better thermo mechanical / cost performance ratio and which finds its applications in the automotive, transport packaging, electrical, electronic and textile industries.

The bio load used is Argan Nut Shell particles of natural origin. The Argan tree (Arganna Spynosa) is one of the most known trees in Morocco [2], [3] mainly on the west coast of the high atlas, 13,000 tonnes of ANS are produced annually [4]. After extracting the Argan oil, the shell is generally poorly exploited and used in combustion. Its price is very low almost $0.5 \mathrm{DH} / \mathrm{Kg}$ [4].The use of Argan Nut Shell particles (ANS) by local populations remains insufficient and must push researchers to enhance them by giving them value in the cultural, environmental and socio-economic context. Several works have studied the reinforcement of polyamides using cellulose [5]-[7].Hence the idea of simulating these Argan Nut Shell particles given their high percentages of cellulose $25.7 \%$, hemi cellulose $34.3 \%$ and lignin $34.5 \%$ [4].

In order to obtain optimal homogenization results, we will simulate several study scenarios in terms of particle content, morphology and size of Argan Nut Shell particles. We will try to randomly model different types of particles (cylinder, ellipsoid, sphero cylinder) reinforced PA66 using the finite element method in comparison with the Mori-Tanaka model offering more advantages in terms of speed of calculations, ease of use and reliability of results. 


\section{MATERIALS AND METHODS}

\subsection{Materials}

\subsubsection{Nylon PA66}

The matrix used is PA66 which is in the class of polyamides also called Nylon considered as one of the thermoplastics offering a light weight and a better thermo mechanical performance-cost ratio [7], [8]. We can cite polyamides $6,66,11,12,46$ etc [9]-[12] which are widely used in the automotive, transportation, packaging, electrical, electronic and textile industries. They are considered as alternatives for metals. PA66 and PA6 are the two most used polyamides.

Reinforcement of Nylon has shown better properties of this polymer by improving its stiffness and strength[13], [14].The synthesis of Nylon 66 is obtained by the poly condensation of adipic acid and hexamethylene diamine. The thermo mechanical properties of Nylon are important considering its tensile properties, good processability and its considerable thermal resistance.

\subsubsection{Argan Nut Shell Particles}

In order to better understand the behaviour of the bio composite studied, we will simulate several study scenarios in order to obtain the optimal results in terms of particle content (Wt.\%), morphology and size of Argan Nut Shell particles. The figure 1 presents these particles after crushing, grinding, chemical treatment and after bleaching.

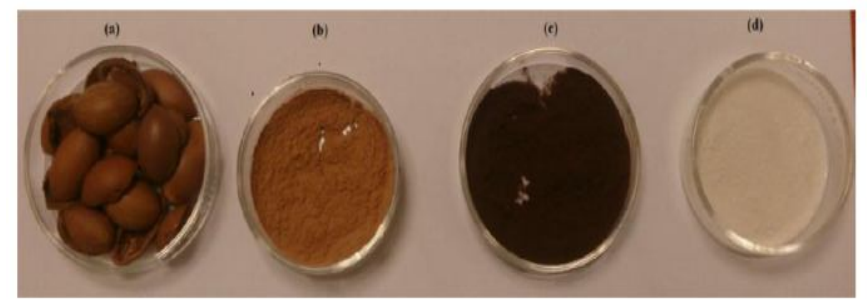

Figure 1: Argan Nut Shell (ANS) [4]

Essabir el al has determined the chemical components in $\%$ of Argan Nut Shell particles as shown in Table 1[4].

Table 1: Chemical components in \% of Argan Nut Shell particles

\begin{tabular}{|c|c|c|c|c|}
\hline & Cellulose & Hemi cellulose & Lignin & Ashes \\
\hline ANS & 25.7 & 34.3 & 34.5 & 5.4 \\
\hline
\end{tabular}

The table 2 presents the characteristics of the different particles used to model the different study scenarios and to determine the optimal thermo mechanical behaviors of the PA66 reinforced by Argan Nut Shell particles.

Table 2: ANS Particles properties

\begin{tabular}{|c|c|}
\hline ANS properties & Values \\
\hline Content & $5,10,15$ and $20 \%$ \\
\hline Morphology & $\begin{array}{c}\text { Cylinder, ellipsoid and sphero } \\
\text { cylinder }\end{array}$ \\
\hline Particle sizes & $0.5,1$ and 10 \\
\hline
\end{tabular}

\subsection{Methods}

The characterization of composites using classical tests is more expensive in terms of test time taking into account all the scenarios of the characterization as well as in terms of the costs of these tests and the difficulty of simulating the composites studied for more specific study conditions.

The use of numerical simulations using current calculation models which are more robust in the modeling the behavior of composites is becoming more and more encouraging for researchers. Numerical is more advantageous in terms of reliability, ease and efficiency of calculations in order to simulate a wide variety of characterization scenarios for shorter calculation times.

In order to model the behavior of PA66 reinforced by Argan Nut Shell particles, several methods of homogenization can be used like the Asymptotic theory [15],Mean Field Homogenization [1] and Finite Element method [16].We will use the two last methods in our modeling due to their ability to better predict the bio composite behavior.

\subsubsection{Finite element method}

The finite element method is able to characterize the complex behaviors of composites. The first idea to work with this method in an article goes back to the American R Clough [17]. Before this article, notions of finite elements were established by Newmark in 1940, Hernnikoff 1941, Courant 1942.Research work that is inspired by finite elements began in the 60 s by taking advantage of the evolution of the numerical models in computer.

The idea of this method is to resolve complex problems in the fields of elasticity, structural calculation, aeronautics and several industrial problems using meshes for the field studied using several elements [18].The use of the finite element method offers advantages of stability and reliability of computation with convergence for reduced times[19].

In order to better understand the thermo mechanical behavior of PA66 reinforced by Argan Nut Shell particles, we will model using this finite element method several study scenarios in order to be able to determine the optimal results in terms of content, morphology and size of Argan Nut Shell particles.

\section{A. Geometry preparation}

The following figure shows the shape of the particles studied.

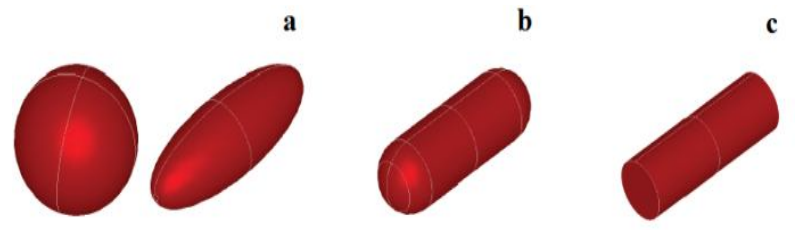

Figure 2: Argan Nut Shell particles shape 


\section{A.1 Position}

\section{A.1.1 Cylindrical particles}

Figure 3 and table 3 present the statistical values for cylindrical particles in $\mathrm{xy}, \mathrm{xz}$ and yz plane.
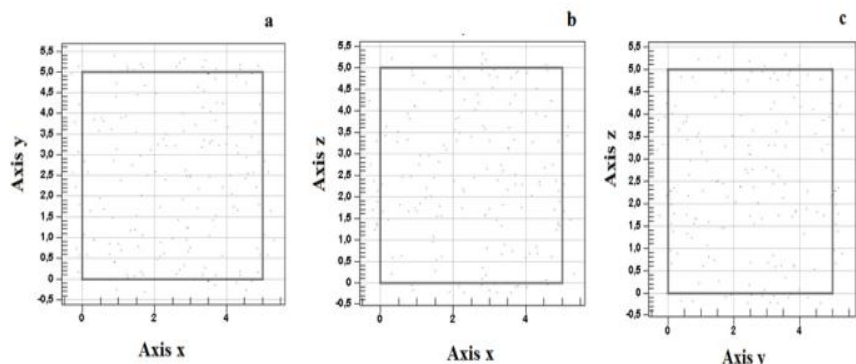

Figure 3: Positions for cylindrical particles in a) $x y$, b) $x z$ and c) $y z$ plane

Table 3: Position for cylindrical particles

\begin{tabular}{|c|c|c|c|c|}
\hline Parameters & Min & Max & Std dev & Mean \\
\hline $\mathrm{x}$ & -0.296 & 5.33 & 1.53 & 2.6 \\
\hline $\mathrm{y}$ & -0.322 & 5.41 & 1.68 & 2.49 \\
\hline $\mathrm{z}$ & -0.24 & 5.34 & 1.57 & 2.49 \\
\hline
\end{tabular}

\section{A.1.2 Ellipsoid particles}

Figure 4 and table 4 present the statistical values for ellipsoid particles in $x y, x z$ and yz plane.
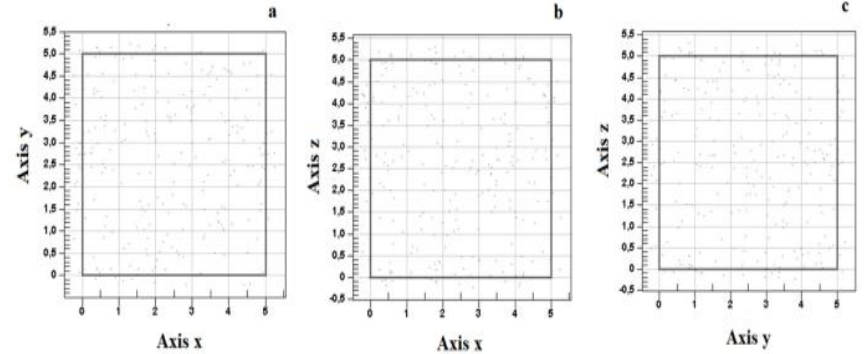

Figure 4: Positions for ellipsoid particles in a) $x y$, b) xz and c) $y z$ plane

Table 4: Position for ellipsoid particles

\begin{tabular}{|c|c|c|c|c|}
\hline Parameters & Min & Max & Std dev & Mean \\
\hline $\mathrm{x}$ & -0.217 & 5.27 & 1.6 & 2.34 \\
\hline $\mathrm{y}$ & -0.219 & 5.23 & 1.56 & 2.6 \\
\hline $\mathrm{z}$ & -0.23 & 5.31 & 1.66 & 2.57 \\
\hline
\end{tabular}

\section{A.1.3 Sphero cylindrical particles}

Figure 5 and table 5 present the statistical values for sphero cylindrical particles in $x y, x z$ and $y z$ plane.
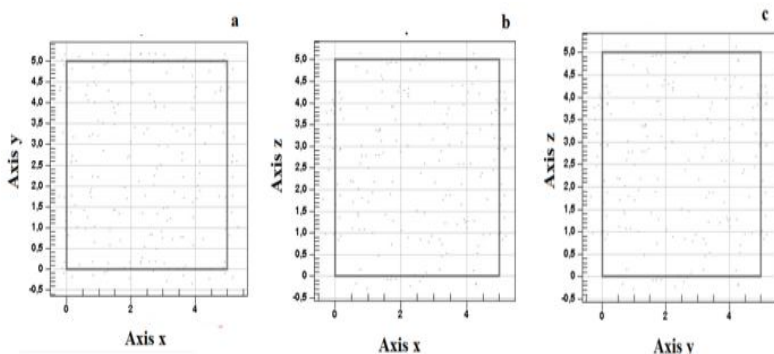

Figure 5: Positions for sphero cylindrical particles in a) $x y$, b) $x z$ and c) yz plane

Table 5: Sphero cylindrical particles position

\begin{tabular}{|c|c|c|c|c|}
\hline Parameters & Min & Max & Std dev & Mean \\
\hline $\mathrm{x}$ & -0.238 & 5.34 & 1.63 & 2.45 \\
\hline $\mathrm{y}$ & -0.358 & 5.19 & 1.71 & 2.46 \\
\hline $\mathrm{z}$ & -0.29 & 5.16 & 1.48 & 2.55 \\
\hline
\end{tabular}

\section{A.2 Nearest particle distance}

Figure 6 and table 6 present the nearest distance distribution for cylindrical particles.

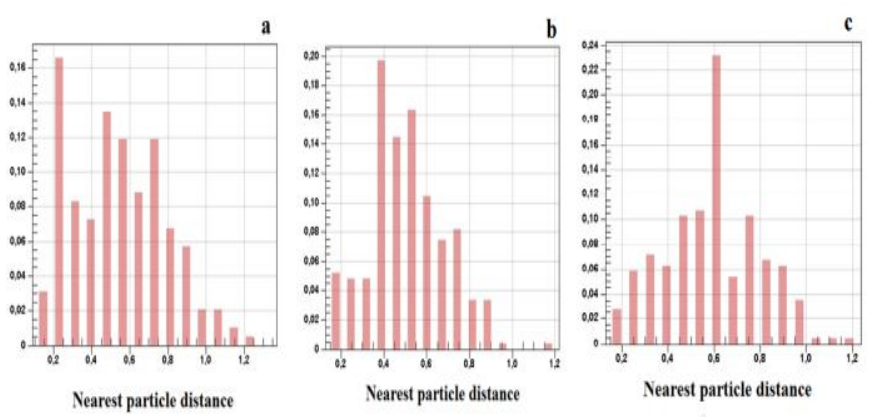

Figure 6: Nearest particle distance for a) Cylindrical, b) Ellipsoid, c) Sphero cylindrical

Table 6: Statistical nearest particle distance

\begin{tabular}{|c|c|c|c|c|}
\hline Parameters & Min & Max & Std dev & Mean \\
\hline Cylindrical & 0.105 & 1.35 & 0.251 & 0.545 \\
\hline Ellipsoid & 0.141 & 1.2 & 0.186 & 0.512 \\
\hline $\begin{array}{c}\text { Sphero } \\
\text { cylindrical }\end{array}$ & 0.143 & 1.22 & 0.211 & 0.596 \\
\hline
\end{tabular}

The figure 7 presents the PA66 geometries reinforced by Argan Nut Shell particles with effective fraction volume in geometry of $0.181431,0.180868$ and 0.180772 respectively for cylindrical morphology, ellipsoid and sphero cylindrical morphologies. 

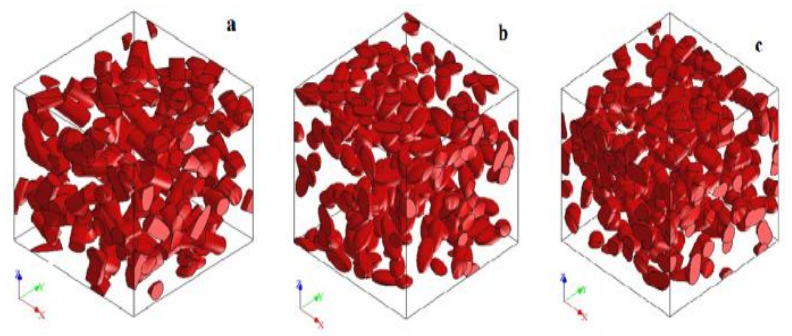

Figure 7: Distribution of particles in geometry a) Cylinder, b) Ellipsoid, c) Sphero cylinder.

\section{B. Incrementation}

The method used to solve our problem is the casi iterative method by choosing a tolerance of 1 E-8 and the incrementation parameters presented in the table 7.

Table 7: Finite element method incrementation

\begin{tabular}{|c|c|}
\hline Parameters & Values \\
\hline Initial time & 0.1 \\
\hline Minimum time & 0.01 \\
\hline Maximum time & 0.1 \\
\hline Final time & 1 \\
\hline Maximum increments & 20 \\
\hline
\end{tabular}

C. Mesh

A good choice of the mesh in the numerical modeling takes into account several parameters like the fast convergence, the good accuracy and the flexibility of use. We will use a non conforming mesh (voxel) [20] which is a brick elements. It is regular and reserved for more complex RVEs where conforming meshes have poorly formed the elements. It is used in several finite element research work showing great power and many advantages for the good prediction of more complex behaviors.

\subsubsection{Mean Field Homogenization}

We will try to model the thermo mechanical behavior of Argan Nut Shell particles reinforced PA66 using the Mori-Tanaka method based on the models of the theory of Mean Field Homogenization (MFH) in order to make comparisons with the finite element method and validate our results obtained. This theory is established by the semi analytical methods with the calculation of the mean volumes of strain and stress fields in each phase at the level of VER. It gives more advantages like the efficiency of calculation.

This Mori-Tanaka model that will be used has several advantages over classical homogenization models such as calculation efficiency and reliability of results [21].

\section{A. Incrementation}

The incrementation time parameters are quoted in the table 8 .

Table 8: Incrementation interval

\begin{tabular}{|c|c|}
\hline Incrementation time & Values \\
\hline Final time & 1 \\
\hline Max time & 0.1 \\
\hline Min time & 0.01 \\
\hline
\end{tabular}

The choice of increment times plays an important role in good numerical modeling. We will use a final time of 1 for the analysis of the software. For the values of maximum and minimum time, we used respectively 0.1 and 0.01 for a better convergence.

\section{B. Tolerance control}

The tolerance control can be carried out by two homogenization and loading tolerance control plans. For these two control plans, we have:

- The target tolerance: To define in absolute value a supplementary stopping criterion.

- The acceptable tolerance: To define the maximal stage of error by considering the iteration is in good convergence.

When reaching a maximum of iterations, we must choose an acceptable tolerance because if it is very small, we will have problems of convergence. In the other case when it is very large, we can fall into unreliable problems results. Hence the importance of the right choice of values that can help us achieve good convergence with more reliable results.

When the number of iterations is under the iterations before control (4), the calculation performs a comparison between the residue and target tolerance when the residue is under the target tolerance. When the number of iterations is above the iterations before control, the comparison will be between the residual and acceptable tolerance. Tables 9 and 10 present respectively the homogenization and loading tolerance control plans.

\begin{tabular}{|c|c|} 
Table 9: Homogenization control plan \\
\begin{tabular}{|c|c|}
\hline Control & Values \\
\hline Acceptable tolerance & $1 \mathrm{E}-005$ \\
\hline Target tolerance & $1 \mathrm{E}-006$ \\
\hline Iterations before control & 4 \\
\hline Max iterations & 20 \\
\hline
\end{tabular}
\end{tabular}

Table 10: Loading control plan

\begin{tabular}{|c|c|}
\hline Control & Values \\
\hline Acceptable tolerance & 1E-005 \\
\hline Target tolerance & 1E-006 \\
\hline Iterations before control & 4 \\
\hline Max iterations & 20 \\
\hline
\end{tabular}

\section{Orientation}

The table 11 presents the orientation parameters used during modeling by the Mori-Tanaka method. 
Table 11: Orientation control

\begin{tabular}{|c|c|}
\hline Control & Values \\
\hline Angle increments & 12 \\
\hline Tolerance in trace & 0.1 \\
\hline
\end{tabular}

The angle of increments used must be between 6 and 36 . We used angle increment of 12 because this number is optimal for better reliability, efficiency in minimal computing time. The orientation tensor tolerance on trace specifies the tolerance computed when calculating with orientations.

The trace must have a value of 1 if not the tolerance of 0.1 that we have chosen will try to set the orientation tensor and set it equal to 1 . The convergence of the calculations cannot be reached if the trace is far from the tolerance.

\section{RESULTS}

\subsection{Mesh of the bio composite}

Choosing the right mesh is important for modeling finite element problems. A good choice of the mesh takes into account several parameters such as the absence of a basic fault, rapid convergence, better accuracy, flexibility of use, efficient programming.

The mesh used in our finite element method is the voxel mesh which is a non conforming brick elements. Convergence is faster than the conforming mesh. The number of voxels is 25 for $\mathrm{X} 1, \mathrm{X} 2$ and $\mathrm{X} 3$.

With a total number of voxels: 15625 . The total elements in PA66 reinforced ANS particles is 15625, the nodes are 17576.
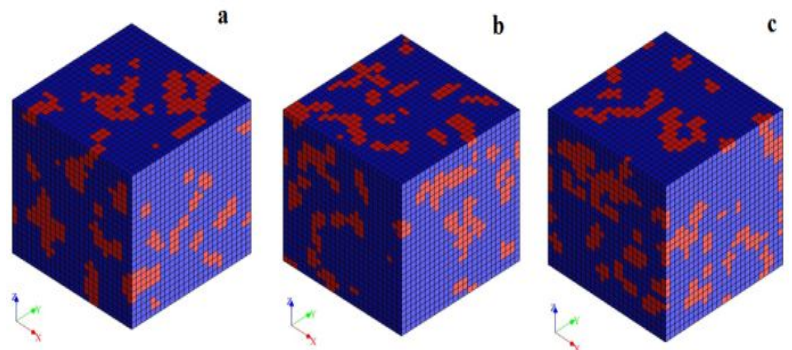

Figure 8: Mesh of PA66 reinforced ANS particles a) cylindrical b) ellipsoid c) sphero cylindrical

Table 12: Elements and volume fraction in PA66 and ANS particles phase

\begin{tabular}{|c|c|c|c|c|}
\hline $\begin{array}{c}\text { Bio } \\
\text { composite }\end{array}$ & Type & Elements & $\begin{array}{c}\text { Mesh } \\
\text { fraction }\end{array}$ & $\begin{array}{c}\text { Geometry } \\
\text { fraction }\end{array}$ \\
\hline ANS & Cyl. & 2822 & 0.1806 & 0.1814 \\
Particles & Ellips. & 2816 & 0.1802 & 0.1809 \\
& Sph.cyl & 2801 & 0.1793 & 0.1808 \\
\hline \multirow{2}{*}{ PA66 } & Cyl. & 12803 & 0.8194 & 0.8186 \\
& Ellip. & 12809 & 0.8198 & 0.8191 \\
& Sph.cyl & 12824 & 0.8207 & 0.8192 \\
\hline
\end{tabular}

\subsection{Random elastic properties of ANS particles and PA66}

The figures 9 and 10 present respectively the stress-strain curve of ANS particles and PA66 at random conditions of bio loading.
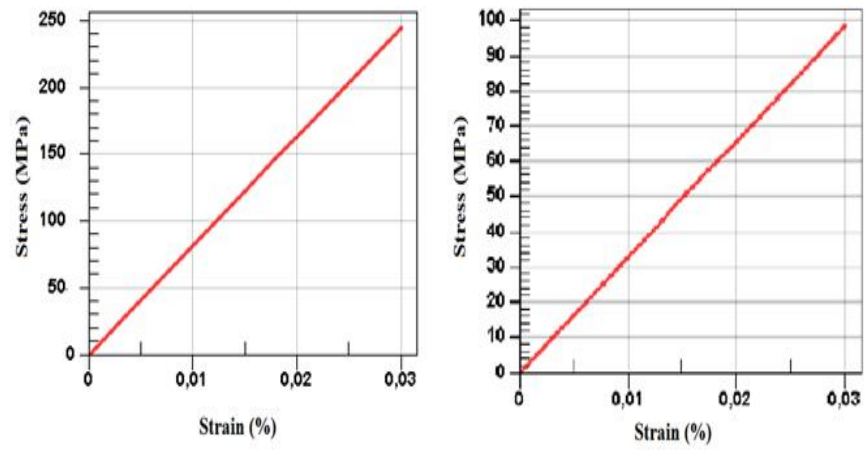

Figure 9: Stress -Strain curve of ANS. Figure 10: Stress -Strain curve of PA66

ANS particles are therefore rigid elastic having a Young's modulus of $8150 \mathrm{MPa}$ and a stress at break of $244.5 \mathrm{MPa}$. The PA66 has a Young's modulus of $3282 \mathrm{MPa}$ and a stress at break of 98.46 MPa. The two curves are purely linear showing a rigidity of the materials used.
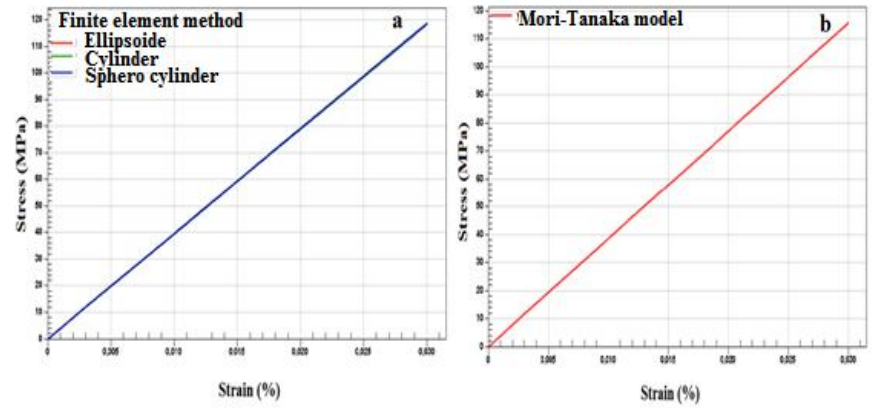

Figure 11: Stress strain curve of the bio composite by the a) Finite element method b) Mori-Tanaka model

The elastic properties of the ANS Particles, PA66 and bio composite are presented by the table 13.

Table 13: Elastic properties using Finite element method (FE) and

\begin{tabular}{|c|c|c|c|}
\hline $\begin{array}{c}\text { Elastic } \\
\text { properties }\end{array}$ & $\begin{array}{c}\text { Stress at } \\
\text { break } \\
\text { (MPa) }\end{array}$ & $\begin{array}{c}\text { Elongation at } \\
\text { break (\%) }\end{array}$ & $\begin{array}{c}\text { Young } \\
\text { modulus } \\
\text { (MPa) }\end{array}$ \\
\hline ANS Particles & 244.5 & 0.03 & 8150 \\
\hline PA66 & 98.46 & 0.03 & 3282 \\
\hline $\begin{array}{c}\text { Bio composite } \\
\text { FE }\end{array}$ & 118.5 & 0.03 & 3950 \\
\hline $\begin{array}{c}\text { Bio composite } \\
\text { M-T }\end{array}$ & 115.6 & 0.03 & 3853.6 \\
\hline
\end{tabular}

The Young's modulus of Argan Nut Shell particles is around $8150 \mathrm{MPa}$ which is stiffer than other classical loads.PA66 reinforced by ANS particles has better elastic 
properties than in the pure state. The two numerical methods give almost the same results as illustrated in figure 11 and table 13, which confirms the power of these two numerical models in predicting even more complex behaviors of bio composites.

The Young's modulus of PA66 improves from 3282 to $3950 \mathrm{MPa}$ by the finite element method and $3853.6 \mathrm{MPa}$ by the Mori-Tanaka model. Also, the stress at break improves from $98.46 \mathrm{MPa}$ to $118.5 \mathrm{MPa}$ by the first numerical method and 115.6 MPa by the latest model. Therefore, we obtain more rigid bio composites under the effect of bio loading using ANS particles.

\subsection{Effect of study parameters on the thermo mechanical behavior of the bio composite}

\subsubsection{Particle content effect (Wt. \%)}

In order to determine the optimal content of ANS particles improving the rigidity of the composite studied, we modeled different contents $(5,10,15$ and $20 \mathrm{Wt} \%)$. The figure 12 presents the results of the Particle Content effect.

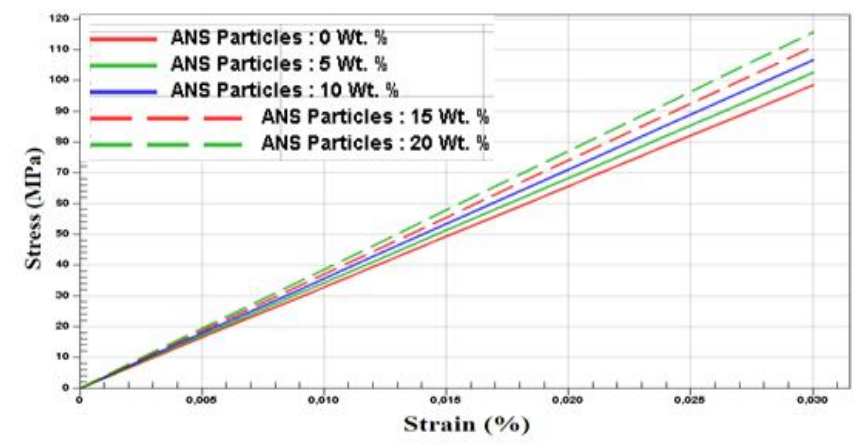

Figure 12: Effect of ANS content (Wt. \%) in the elastic curves of the bio composite

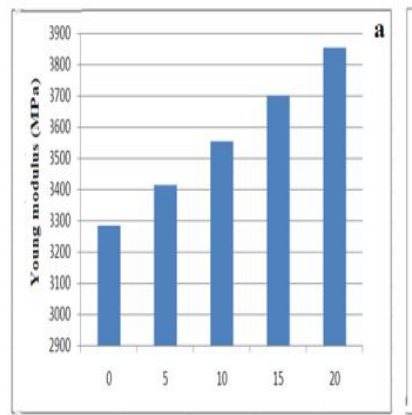

Particle Content (wt. \%)

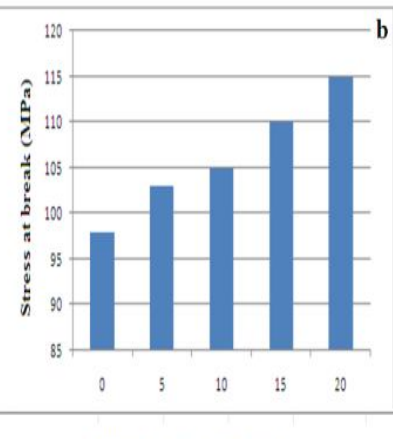

Particle Content (wt. \%)
Figure 13: ANS particles effect in a) Young modulus of the bio composite, b) stress at break of the bio composite

According to Figure 12 the elastic properties increase as the particle content increase. It is shown in figure 13.a that the Young modulus increase from $3282 \mathrm{MPa}$ at $0 \mathrm{Wt}$. \% of ANS particles to $3853.6 \mathrm{MPa}$ at $20 \mathrm{Wt}$. \% of particles.

Also, the stress at break increases from $98 \mathrm{MPa}$ at $0 \mathrm{Wt} . \%$ to $115 \mathrm{MPa}$ at $20 \mathrm{Wt}$. \% as shown in figure 13.b.

\subsubsection{Effect of the morphology}

In order to study the effect of ANS particles morphology on the behavior of the studied polymer, we modeled three different shape of particles (cylinder, ellipsoid and sphero cylinder) .The figure 14 present the effect of ANS particles morphology on PA66 at a fixed orientation $\left(0^{\circ}\right)$ and at b) at random orientation.
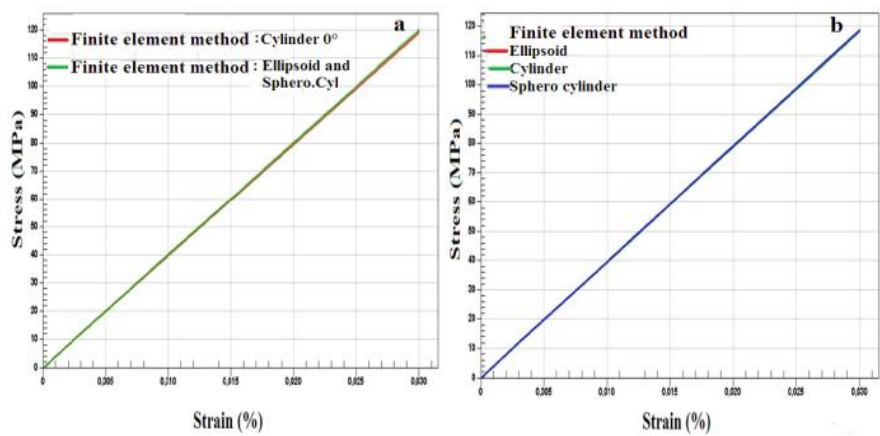

Figure 14: Effect of ANS particles morphology in the PA66 at a) a fixed orientation $\left(0^{\circ}\right)$; b) a random orientation

From the figure 14, the particles morphology (cylinder, ellipsoid or sphero cylinder) does not affect the behavior of the PA66. The elastic properties (Young's modulus, Stress at break) are almost the same at a fixed and random orientation except in the $90^{\circ}$ case where the ellipsoid particles are slightly less rigid as will also be explained in the following paragraph.

\subsubsection{Effect of particle size}

In order to study the effect of ANS particles size on the behavior of the polymer studied, we modeled several sizes $(0.5,1$ and 10). The figure 15 presents the tensile curves obtained for these different sizes.

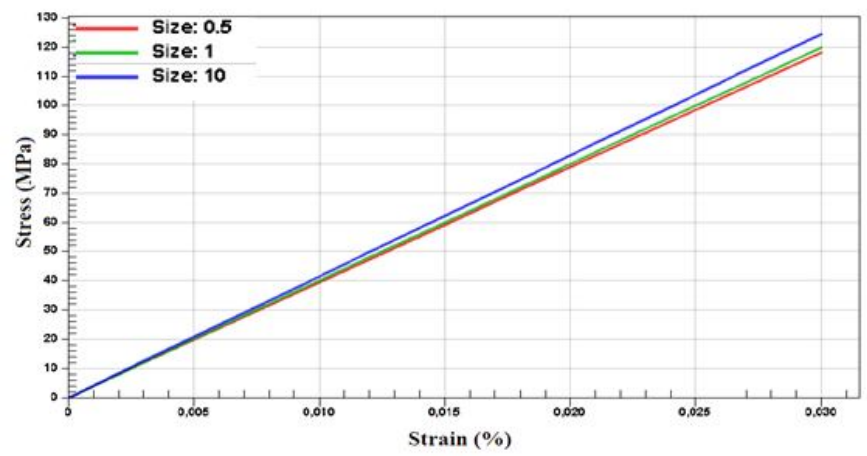

Figure 15: Tensile curves of the bio composite for different particle size

The results obtained in the figure 15 show that the behavior of PA66 reinforced by Argan Nut Shell particles change by the variation of particle size from 0.5 to 10 . The rigidity increases by decreasing the particle size in terms of the improved Young modulus and the stress at break which becomes greater. 
We can deduce that these small sizes do not favor the formation of aggregates leading to better interactions and compatibility with PA66 matrix.

It can be deduced that bio loading using Argan Nut Shell particles led to an improvement in the mechanical properties of Nylon PA66. The findings of the present research work confirm the results obtained by Essabir et al. [4] showing the improvement in Polypropylene properties by the same bio load studied.

Tatane et al. also demonstrated the good effect of Argan Nut Shell particles on thermal and mechanical behavior of compressed earth blocks [22]. Moumen et al. determined the improvement in the micromechanical behavior of Polypropylene reinforced by Snail Shell particles and the good compatibility of these bio loads with the polypropylene matrix [1]. Liu also showed the improvement of matrix properties by using jute fibers [23].

We can summarize that the Finite Element Method and the Mori-Tanaka Model [24]-[26] are powerful in predicting more complex bio composite behaviors and this bio load compared to other from natural origin (Snail shell, jutes fibers...) will therefore be considered as an alternative for classical loads in order to obtain an environment friendly eco composite with much better mechanical properties.

\section{CONCLUSION}

In this study, we have presented the important role of bio loading to meet the needs of industrialists, the requirements of regulations, environmental constraints, and sustainable development and to move away from the classical loads affecting the environment.

We modeled the behavior of polyamide PA66 reinforced by Argan Nut Shell particles thanks to the finite element method and the Mori-Tanaka model which have a great power to find the equivalent homogenous bio composite which has the same properties as the heterogeneous materials used, they have an ease of use, speed of computing and the accuracy of predicting the final behavior of the bio composite studied. We can summarize that several parameters affect the PA66 reinforced by Argan Nut Shell particles.

The study of the different results of the modeling carried out numerically for several types of particles (Cylinder, ellipsoid and sphero cylinder) shows that the reinforcement of polyamide 66 gives better mechanical properties than in the pure state.

The study of the different parameters on the final behavior of the bio composite shows that the mechanical characteristics of the bio composite become more optimal by adding more particle content (Wt\%) at an optimal value of $20 \mathrm{Wt}$ and by decreasing the Argan Nut Shell particles size.

\section{REFERENCES}

1. A. Moumen, M. Jammoukh, L. Zahiri, and K. Mansouri, "Study Of The Optimal Micromechanical Behavior Of A Polymer Reinforced By Snail Shell Particles Using The Mori-Tanaka Numerical Model," in 2020 IEEE International conference of Moroccan Geomatics (Morgeo), 2020, pp. 1-6.

2. B. Matthäus, D. Guillaume, S. Gharby, A. Haddad, H. Harhar, and Z. Charrouf, "Effect of processing on the quality of edible argan oil," Food Chem., vol. 120, no. 2, pp. 426-432, 2010.

3. Z. Charrouf, M. Hilali, O. Jauregui, M. Soufiaoui, and D. Guillaume, "Separation and characterization of phenolic compounds in argan fruit pulp using liquid chromatography-negative electrospray ionization tandem mass spectroscopy," Food Chem., vol. 100, no. 4, pp. 1398-1401, 2007.

4. HAMID ESSABIR, "Bio-composites à base de coque de noix d'arganier : Mise en ouvre, caractérisation et modélisation du comportement mécanique.," p. 184, 2015.

5. J. Xu, "Evaluation of Mechanical Properties of Recycled Polyamide-Cellulose Fiber Composite by," 2016.

6. X. Xiaolin, "Cellulose Fiber Reinforced Nylon 6 or Nylon 66," no. December, pp. 1-228, 2008.

7. S. Aitha and N. Vasanthan, "Effect of cellulose nanocrystals on crystallization, morphology and phase transition of polyamide 6," Compos. Interfaces, vol. 27, no. 4, pp. 371-384, 2020.

8. C. S. Lee, H. J. Kim, A. Amanov, J. H. Choo, Y. K. Kim, and I. S. Cho, "Investigation on very high cycle fatigue of PA66-GF30 GFRP based on fiber orientation," Compos. Sci. Technol., vol. 180, no. May, pp. 94-100, 2019, doi: 10.1016/j.compscitech.2019.05.021.

9. X. Yu, X. Wang, Z. Zhang, S. Peng, H. Chen, and X. Zhao, "High-performance fully bio-based poly(lactic acid)/ polyamide11 (PLA/PA11) blends by reactive blending with multi-functionalized epoxy," Polym. Test., vol. 78, no. June, p. 105980, 2019, doi: 10.1016/j.polymertesting.2019.105980.

10. A. N. Chen et al., "Mullite ceramic foams with controlled pore structures and low thermal conductivity prepared by SLS using core-shell structured polyamide12/FAHSs composites," Ceram. Int., vol. 45, no. 12, pp. 15538-15546, 2019, doi: 10.1016/j.ceramint.2019.05.059.

11. K. Mankotia, I. Singh, and R. Singh, "On effect of almond skin powder waste reinforcement in PA6: Rheological, thermal and wear properties," Mater. Today Proc., 2020.

12. B. Suresha, G. Hemanth, R. Hemanth, and N. P. Lalla, "Role of graphene nanoplatelets and carbon fiber on mechanical properties of PA66/thermoplastic copolyester elastomer composites," Mater. Res. Express, vol. 7, no. 1, p. 15325, 2020. 
13. A. Pertuz, S. Díaz-Cardona, and O. A. G. Estrada, "Fatigue in Continuous Fibre Reinforced Thermoplastic Composites," 2020.

14. S. Krishna and C. M. Patel, "Computational and Experimental Study of Mechanical Properties of Nylon 6 Nanocomposites reinforced with Nanomilled Cellulose," Mech. Mater., p. 103318, 2020.

15. Z. He and M.-J. Pindera, "Locally exact asymptotic homogenization of periodic materials under anti-plane shear loading," Eur. J. Mech., vol. 81, p. 103972, 2020.

16. A. Lakhdar, M. Jammoukh, L. Zahiri, K. Mansouri, A. Moumen, and B. Salhi, "Numerical and Experimental Study of the Behavior of PVC Material Subjected to Aging," in 2020 1st International Conference on Innovative Research in Applied Science, Engineering and Technology (IRASET), 2020, pp. 1-6.

17. R. W. Clough, "The finite element method in plane stress analysis," in Proceedings of 2nd ASCE Conference on Electronic Computation, Pittsburgh Pa., Sept. 8 and 9, 1960, 1960.

18. V. Manet, "La Méthode des éléments finis. Vulgarisation des aspects mathématiques. Illustration des capacités de la méthode," URL https//hal. Arch. fr/cel-00763690/(cf. pages 11, 23, 24), 2012.

19. D. Ashok, S. Puhan, R. Pradhan, P. K. Babu, and Y. S. Reddy, "An Experimental Investigation of New Hybrid Composite Material Using Ramie-Flax and Its Mechanical Properties Through Finite Element Method," in Recent Trends in Mechanical Engineering, Springer, 2020, pp. 431-446.

20. Y. Sinchuk, Y. Pannier, R. Antoranz-Gonzalez, and M. Gigliotti, "Analysis of moisture diffusion induced stress in carbon/epoxy 3D textile composite materials with voids by $\mu$-CT based Finite Element Models," Compos. Struct., vol. 212, pp. 561-570, 2019.

21. M. Barral, G. Chatzigeorgiou, F. Meraghni, and R. Léon, "Homogenization using modified Mori-Tanaka and TFA framework for elastoplastic-viscoelastic-viscoplastic composites: Theory and numerical validation," Int. J. Plast., vol. 127, p. 102632, 2020.

22. M. Tatane et al., "Effect of Argan Nut Shell Powder on Thermal and Mechanical Behavior of Compressed Earth Blocks," Int. J. Appl. Eng. Res. ISSN, vol. 13, no. 7, pp. 973-4562, 2018.

23. X. Improvement on the interfacial compatibility of jute fiber-reinforced polypropylene composites by different surface treatmentsLiu, S.-J. Hao, Y.-H. Cui, and H. Chen, "Improvement on the interfacial compatibility of jute fiber-reinforced polypropylene composites by different surface treatments," J. Ind. Text., vol. 49, no. 7, pp. 906-922, 2020.

24. R. C. Mamat, A. Kasa, and S. F. M. Razali, "Performance prediction of road embankment on soft soil stabilized with prefabricated vertical drains using numerical method," Int. J. Adv. Trends Comput. Sci.
Eng., vol. 8, no. 4, pp. 1601-1608, 2019, doi: 10.30534/ijatcse/2019/85842019.

25. N. Ravindran and H. B. Mohamed, "Finite element analysis and comfort assessment conducted on the visual aid design for monocular vision patients," Int. J. Adv. Trends Comput. Sci. Eng., vol. 9, no. 2, pp. 951-955, 2020, doi: 10.30534/ijatcse/2020/07922020.

26. A. Moumen, M. Jammoukh, L. Zahiri, and K. Mansouri, "Numerical modeling of the thermo mechanical behavior of a polymer reinforced by horn fibers," Int. J. Adv. Trends Comput. Sci. Eng., vol. 9, no. 4, pp. 6541-6548, 2020, doi: 10.30534/ijatcse/2020/342942020. 